\title{
O HUMANISMO NA FORMAÇÃO DO ADMINISTRADOR: CASO UFSC
}

\author{
RicARdo Niehues Buss* \\ JosÉ NILSON REINERT**
}

Recebido em: 15 de junho de 2008

Aprovado em: 19 de novembro de 2008

\footnotetext{
* Mestre em Administração - CPGA/UFSC, Coordenador do Curso de Administração da Faculdade Católica Dom Orione-FACDO.E-mail: rnbuss@yahoo.com.br

**Dr. em Administração de Empresas pela EAESP-FGV, Prof. Do Curso de Graduação e Mestrado em Administração - UFMT. E-mail: icaro.phenix@uol.com.br
}

Resumo: O presente estudo teve como objetivo descrever e analisar a formação humanista oferecida aos estudantes do Curso de Graduação em Administração da Universidade Federal de Santa Catarina (UFSC), comparando o currículo do ano de 1978, o primeiro currículo disponível, com o currículo do ano de 2006. Este trabalho é parte de uma dissertação de mestrado que objetivou conhecer a situação do Curso de Administração da UFSC perante o discurso do humanismo. A pesquisa teve caráter descritivo exploratório. Da análise realizada, conclui-se que o ensino humanista diminuiu de forma expressiva no Curso de Graduação em Administração da UFSC e que o mesmo apresenta características de formação especializada.

Palavras chave: Humanismo. Especialização. Multidisciplinaridade. Ensino. Currículo.

\section{HUMANISM IN THE EDUCATION OF THE ADMINISTRATOR: THE UFSC CASE}

Abstract: The purpose of the present study was to describe and analyze the humanistic education offered to the students of the Undergraduate Administration Program of the Federal University of Santa Catarina (UFSC), comparing the first available curriculum, of 1978, to the curriculum of the year 2006. This work is part of a master's thesis, that researched the situation of the Administration Program at UFSC within the discourse of humanism. This was a descriptive exploratory research. From the analysis, one can conclude that humanistic teaching significantly decreased in the Undergraduate Administration Program at UFSC and that it presents characteristics of specialized education.

Key words: Humanism. Specialization. Multidisciplinarity. Education. Curriculum.

\section{Introdução}

A Universidade está hoje em contato com todas as forças da sociedade. O próprio crescimento do saber não se faz mais apenas por indivíduos, mas por equipes, e esse crescimento já está se concentrando por áreas e não mais por pessoas. 
Segundo Morin (2002), a universidade é conservadora, regeneradora e geradora porque conserva, memoriza, integra, ritualiza uma herança cultural de idéias, valores e saberes; regenera essa herança ao reexaminá-la e transmiti-la. Gera saberes, idéias e valores que passam então a fazer parte da herança. Elas são, em grande parte, responsáveis pelo desenvolvimento econômico e tecnológico; devem dedicar-se à regulação e ao controle deste processo e tratar de assegurar o desenvolvimento humano. (TEIXEIRA, 1964)

As Universidades Contemporâneas vivem cada vez mais em função da sociedade e da procura de soluções para os problemas e vêm sendo consideradas também como formadoras de profissionais que contribuam para a satisfação de demandas sociais.

Atualmente, a procura por estas Instituições de Ensino Superior tem um propósito diferente, na maioria dos casos, a busca do diploma, através de cursos de graduação abarrotados de disciplinas profissionalizantes. As Universidades desviam-se, muitas vezes, do propósito de investigação e disseminação da verdade, procurando atender às necessidades imediatistas do mercado e das pessoas que procuram a capacitação.

As Universidades, com o passar do tempo, vêm se reduzindo a um local onde vários cursos são ministrados em vários níveis, conforme Crippa (1966), com o objetivo principal de preparar técnicos e profissionais para o mercado, distanciando-se cada vez mais de sua principal finalidade, a busca pela verdade.

Contudo, às Universidades, de um modo geral, sempre parece restar um mínimo de sensibilidade às necessidades maiores da sociedade. Confundir a formação universitária com a preparação do estudante só para o desempenho de determinadas atividades é empobrecer, limitar uma formação ampla e criativa para privilegiar o saber imediato, o aprendizado da execução, oposto ao da humanização do próprio homem.

Somente a formação técnica não basta. A formação depende da educação do homem como pessoa, que entenda seus semelhantes e tenha uma visão crítica do mundo e criativa o suficiente para elaborar novas soluções perante as mudanças da sociedade e do mundo.

Corroborando com o tema, o artigo "Reforma da Educação Superior Brasileira”, publicado no portal do MEC (BRASIL, 2005), revela a preocupação crescente em atender ao mercado, não com profissionais especialistas conhecedores de uma determinada atividade, mas com profissionais com características mais humanistas: com uma formação mais generalista, conhecedores de línguas e que saibam se relacionar trabalhando em grupo. 
O artigo "Cursos de graduação em administração: a necessidade de um novo enfoque", de Reinert (2002) alerta que os currículos podem não estar mais correspondendo às expectativas sociais, necessitando de profundas mudanças. Os cursos de graduação, em especial os de administração, possuem uma performance de alta especialização, entendida, neste caso, como focada em disciplinas eminentemente técnicas e de formação profissionalizante.

Ao se buscar uma compreensão mais aprofundada deste discurso, pode-se perceber que os cursos e as universidades estão voltados para uma formação profissionalizante, visando atender essa demanda de mercado, deixando de lado uma educação mais ampla que enfatize o desenvolvimento total do indivíduo.

Esta é uma realidade que vem sendo discutida há muito tempo por grandes pensadores como Kant, Fichte, Schleiermacher, Newman, Jaspers, dentre outros, que apóiam uma formação universalista e mais completa do homem, pelo menos em sua base de formação. Essa, por sua vez, só se torna possível através das ciências humanas, principalmente da filosofia.

A presente pesquisa tem como tema o humanismo na formação do administrador e, foi realizada no Curso de Graduação em Administração da UFSC, no qual foi levantada a participação de disciplinas de formação humanística no currículo do curso. Espera-se que esta venha fornecer subsídios importantes para discussões, análises, e de alguma forma, contribua para a evolução dos conceitos que envolvem a aprendizagem da administração na universidade.

\section{Humanismo}

Segundo Paviani e Botomé (1993), o humanismo é conhecido como movimento intelectual que germinou durante o século XIV e no final da Idade Média, e alcançou maturidade no Renascimento. Buscava construir uma nova imagem do mundo a partir da permanência de elementos do passado. É em nome do humanismo que o homem, mesmo temeroso, começa a separar-se da grande ordem do universo, para ser seu espectador privilegiado.

O humanismo é considerado uma doutrina, conforme Ferreira (1975), um movimento que cultuava as línguas e literaturas greco-latinas, com o objetivo de formar o espírito humano pela cultura literária ou científica.

Na concepção de Paviani e Dal Ri Jr. (2000), o humanismo objetivava o desenvolvimento das qualidades do homem, pregando que todas as pessoas têm dignidade e valor, devendo fazer jus ao respeito dos outros. O homem é o centro de seu estudo e, através desta concepção de mundo, pode-se considerar o humanismo a origem de todo o pensamento moderno. 
Segundo Aristóteles, "o conhecimento do ser é imprescindível para fornecer bases sólidas às ciências (física, astronomia, biologia etc.), que se ocupam de aspectos particulares da realidade” (ABRÃO, 2004, p. 61). Através desse conhecimento as ciências se unificaram em um todo coerente sem o que só haveria explicações particulares de coisas particulares.

O humanismo estuda valores considerados essencialmente humanos, estudo das humanidades, um sentido mais helenístico que se refere à história, retórica, poesia, gramática e filosofia, relata Basbaum (1981). Nesse sentido, mais técnico, o humanismo compõe-se basicamente da filosofia, das artes e das línguas antigas.

Sartor (2004, p. 141) afirma que no mundo contemporâneo "o humanismo tem explicitado a possibilidade de o homem tomar suas próprias decisões numa economia que parece dominar o mundo da política, tal qual hoje as finanças regem o destino da humanidade e das gerações futuras”. Isso constitui um reducionismo da vida humana, por ela deixar-se guiar por fenômenos econômicos, onde a formação das pessoas fica submetida às diretrizes do mercado, ao invés dos da vida.

As ciências humanas são definidas por Ferreira (1975), como sendo a ciência que estuda o comportamento do homem, seja na sua coletividade ou na sua individualidade, através da psicologia, filosofia, lingüística e história.

A Ciência não apenas se diferencia da filosofia, como criou uma relação complexa ao longo da história de dependência e interdependência, segundo Paviani e Botomé (1993). Essa relação faz com que, em uma visão atualizada, a Ciência coloque certos problemas à Filosofia, deixando de ser uma espécie de produto da mesma. Eis aí a importância do humanismo para a Ciência, através de seu principal representante, a Filosofia.

\subsection{Formação e Humanismo}

A finalidade da universidade para Ortega e Gasset, citados por Tobias (1969), é a ministração do ensino superior, para formar o homem de modo que ele não se torne um bárbaro. Dessa forma, a definição de universidade fica sendo como a de instituição que ensina o estudante a ser homem culto e bom profissional.

Nesse sentido, a universidade é o lugar do saber universal, para tanto é preciso ministrar esse conhecimento universal no nível básico e, posteriormente o conhecimento especializado.

Para Freire (1996), a formação vai muito mais além do que a preparação técnico-científica. Segundo o autor, infelizmente o que é válido atualmente é 
o "pragmatismo" pedagógico, ou seja, o treino técnico-científico, fundamentalmente voltado para a ditadura do mercado.

O progresso científico e tecnológico que não responder fundamentalmente aos interesses humanos, às necessidades de nossa existência, perde a significação. Esse avanço tecnológico haveria de corresponder à formação de homens e mulheres, a fim de que estes tenham uma vida mais plena. Freire (1996, p. 143) relata que há um "caráter desesperançoso, fatalista, antiutópico de uma tal ideologia em que se forja uma educação friamente tecnicista e se requer um educador exímio na tarefa de acomodação ao mundo e não na de sua transformação". O que se vê, portanto, é um educador com pouco de formador e muito de treinador e transferidor de saberes.

Segundo a feminista Camille Paglia (apud SUWWAN, 2006), uma das intelectuais mais influentes dos Estados Unidos, "o pensamento independente foi universalmente silenciado ou isolado. A educação universitária está cada vez mais estéril por causa da autodestruição das ciências humanas”.

O problema da formação especializada pode ter origem na compartimentalização do conhecimento, onde as disciplinas transformaram-se em um reduto de entendidos quanto à produção de um determinado tipo de conhecimento. Para Paviani e Botomé (1993), alguns critérios políticos e administrativos mostramse desvirtuados de suas funções, parecendo estarem substituindo os critérios científicos, epistemológicos, educacionais e profissionais, quando deveriam ser auxiliares e complementares.

Conforme Tobias (1969), a universidade passou a viver para a sociedade em função do progresso e da modernização, participando cada vez mais e ativamente em projetos governamentais e comerciais. Sua finalidade, que antes era a busca da verdade, passa a ser a sociedade, com o ideal de formar o homem de organização. No entanto, a prestação de serviços e o servir à comunidade, deveriam ser finalidades derivadas e secundárias da universidade, que deveria manter a busca da verdade como finalidade primeira. Esses erros, dentre eles o profissionalismo e o tecnicismo, sobre a finalidade da universidade, são explicados por Tobias a seguir:

- O profissionalismo: muito discutido e combatido por muitos pensadores, que são contrários à idéia da formação de uma profissão, muitas vezes rendosa, como sendo a finalidade primeira da universidade e não a busca pela verdade;

- O tecnicismo: do mesmo modo como o profissionalismo, a universidade não deve formar técnicos, treinados para exercer determinada 
função; isto poderia ser adquirido com a experiência após a universidade;

- A departamentalização: com ela a universidade isola-se, regredindo, muitas vezes, a categoria de faculdades isoladas, prejudicando a busca pelo conhecimento;

- A docência: muito importante para a divulgação, transmissão dos saberes, da verdade que é realmente a principal finalidade;

- A moralização: a educação moral, por mais que seja boa, deve ser ministrada por outra instituição e não pelo templo do saber;

- O nacionalismo espúrio ou o regionalismo barato: perigoso dentro da universidade, já que ela é cosmopolita e universalista, não deve possuir limites ou inclinações regionalistas;

- Ministrar "cultura geral": a cultura geral verdadeira é aquela que provém em especial da filosofia e não a proveniente de ensinamentos que negam esse fato;

- Pesquisa ou investigação: a investigação é a que confunde mais com a finalidade primordial da universidade, não que ela não seja, só que depois do conhecimento da verdade é que vem a investigação;

- A sociedade: através da busca pela verdade é que a sociedade deveria ser beneficiada pela universidade.

Estas podem não ser as finalidades principais da Universidade, mas isso não quer dizer que não façam parte da sua finalidade como fins intermediários. Desta forma, só o conhecimento da verdade não constitui uma Universidade. A junção de suas derivações é necessária para que esta ocorra. "A causa, portanto, da universidade é a sociedade que, pela investigação e docência, se ordena à verdade.” (TOBIAS, 1969, p. 213)

Nesse sentido, a educação humanista para Sartor (2004, p. 146), “consiste em salvaguardar o saber e, por isso mesmo, defender o homem do abuso da técnica, bem como do uso inescrupuloso pelo inculto”.

\subsection{Formação multidisciplinar}

O conhecimento nas universidades encontra-se cada vez mais fragmentado, enclausurado em estruturas disciplinares muitas vezes com pouca comunicação 
ou até mesmo incomunicáveis. Os debates sobre as estruturas de produção e transmissão do conhecimento são mais intensos a cada dia.

Conforme Anastasiou (2004), a fragmentação das ciências desenvolveu áreas especializadas de conhecimento permutadas em matérias e disciplinas de ensino nas propostas curriculares. Dessa permuta se estabelecem diferentes graus de relações disciplinares: multidisciplinaridade, interdisciplinaridade e transdisciplinaridade. Portanto, a multidisciplinaridade é caracterizada pela proposição simultânea de disciplinas, de forma somática, sem que se explicitem relações entre elas; é o currículo grade ou coleção.

A estrutura multidisciplinar supõe uma justaposição de conteúdos de disciplinas desiguais ou uma integração de conteúdos numa mesma disciplina, procurando-se um nível de integração de métodos, teorias e conhecimentos. Ou seja, "caracteriza-se pela justaposição de matérias diferentes, oferecidas de maneira simultânea, com a intenção de esclarecer alguns de seus elementos comuns, mas na verdade nunca se explicam claramente as possíveis relações entre elas.” (SANTOMÉ, 1998, p. 17)

Na multidisciplinaridade, o estudo é visto sobre diferentes olhares em forma de agrupamentos disciplinares, mas sem a intenção de conceitos, procedimentos e atitudes. $\mathrm{O}$ trabalho entre o sujeito não é cooperativo, sendo que cada disciplina mantém seus próprios objetivos, formas e dinâmicas de trabalho. Dessa forma para Santomé (1998), um dos grandes problemas da multidisciplinaridade está na falta de contextualização com outros saberes produzidos pelos sujeitos em outros espaços de aprendizagem. Isso resulta em conteúdos apresentados sem relação com o cotidiano ou com as vivências com o sujeito.

A multidisciplinaridade é definida como sendo um conjunto de disciplinas a serem trabalhadas simultaneamente, sem que apareçam as relações que possam existir entre elas, destinando-se a um sistema de um só nível e de objetivos únicos, sem nenhuma cooperação. A multidisciplinaridade corresponde à estrutura tradicional de currículo nas universidades, o qual se encontra fragmentado em várias disciplinas.

Deste modo, recorre-se a informações de várias disciplinas para estudar um determinado elemento, não se preocupando em interligá-las umas com as outras. Assim, cada uma contribui com informações próprias do seu campo de conhecimento, sem considerar que exista uma integração entre elas.

A multidisciplinaridade, segundo Piaget (2003), propõe uma estrutura para a solução de um determinado problema, utilizando informações de duas ou mais especialidades sem que as disciplinas levadas a contribuir para aquelas que a utilizam sejam modificadas ou enriquecidas. 
A origem da multidisciplinaridade encontra-se na idéia de que o conhecimento pode ser dividido em partes (disciplinas), resultado da visão cartesiana e, depois, numa visão cientificista a disciplina é percebida como um tipo de saber específico que possui um objeto determinado e reconhecido, bem como conhecimento e saberes relativos a este objeto e métodos próprios. Constituise, então, a partir de uma determinada subdivisão de um domínio específico do conhecimento. A tentativa de estabelecer relações entre as disciplinas é que dará origem a chamada interdisciplinaridade.

As questões curriculares, por sua vez, não deveriam ser tratadas de forma linear e restrita apenas aos aspectos técnicos e científicos; elas também deveriam possuir uma abordagem que possibilitasse convergir o ensino técnico com aspectos humanísticos.

A multidisciplinaridade, mesmo sendo um mecanismo simples de comunicação entre as disciplinas, pode proporcionar essa ligação entre o tecnicismo e o humanismo, com maior comunicação e interação entre disciplinas diferentes.

\subsection{Super especialização versus humanismo}

Hoje, a especialização e a superespecialização fazem parte do cenário atual das universidades, que estão cada vez mais buscando atender às necessidades de profissionais para o mercado de trabalho. Essa formação, no entanto, centrada no tecnicismo e no profissionalismo, pode não estar atendendo às necessidades das organizações e nem mesmo dos profissionais sem que eles necessariamente saibam disso.

A especialização do trabalhador significa, de fato, uma desqualificação do mesmo, segundo Reinert (1981), já que o trabalhador passa a exercer, muitas vezes, uma única tarefa de forma exaustiva, monótona e repetitiva, bloqueando qualquer criatividade que possa existir na sua atividade.

Para Teixeira (1930), a superespecialização na indústria faz com que o trabalho passe a ser uma simples tarefa e que o trabalhador sinta-se como uma simples "peça da máquina", não havendo lugar para pensar, nem mesmo para saber se o que está fazendo vale à pena.

A especialidade deve ser tratada como parte de uma totalidade e não pode ser vista como fora dela. Segundo Bazzo (1998), este processo é difícil de ser realizado e deve ser feito por meio de uma formação que privilegie o tratamento interdisciplinar da especialidade e uma formação disciplinar com conteúdos de humanidades. 
A superespecialização dos estudantes pode gerar problemas sociais, cegando o profissional para qualquer consideração que ultrapasse o âmbito de suas competências técnicas. Um profissional especialista irá se comportar em todas as questões que ignora, conforme Sartor (2004), não como um ignorante, mas como um sábio petulante no assunto.

Coelho (2006) alerta que "confundir formação profissional com preparação do estudante para o desempenho de determinadas atividades é empobrecê-lo e assumir o caminho que, no curto e, sobretudo, no médio e longo prazos, limita as possibilidades de colocação no mercado de trabalho".

De acordo com Freire (1996, p. 33), "transformar a experiência educativa em puro treinamento técnico é amesquinhar o que há de mais fundamentalmente humano no exercício educativo: o seu caráter formador". E ao referir-se à capacitação em torno dos saberes instrumentais, Freire argumenta que estes jamais podem prescindir a formação ética.

Um perfil ideal de profissional que as organizações necessitam, segundo Linsingen (2005), não privilegia apenas o conhecimento técnico específico, mas também uma boa capacidade de comunicação oral e escrita, de relacionamento, interatividade e criatividade.

O profissional generalista ganha cada vez mais espaço no mundo do trabalho por saber um pouco de cada área, ter conhecimento geral, ser versátil e por adaptar-se facilmente às mudanças. Segundo Linsingen, o estudante deveria possuir uma formação geral, com caráter conservador e transformador do sentir, pensar e agir humanamente, centrado em uma visão de sociedade que interage, que se globaliza sem perda de identidade e que opera de modo cada vez mais interconectado, ou integrado em rede.

Pode ser percebido que, apesar de uma tendência tecnicista do sistema de ensino-formação, os aspectos humanísticos tornam-se cada vez mais presentes_no discurso da formação profissional, embora não necessariamente, na prática. Em resumo, de uma maneira geral, parece ficar cada vez mais evidente a importância do humanismo para a formação de um profissional, mesmo quando este aspecto é considerado por autores com uma forte ênfase no chamado mercado.

\subsection{O ensino de administração}

O ensino de administração, no Brasil, está relacionado ao processo de desenvolvimento do país. Segundo Fischer (1985), origina-se através de um acordo da política de cooperação técnica entre Brasil e Estados Unidos (EUA), no período de 1950 a 1960, que servia como instrumento de capacitação de recursos humanos. Essa política de cooperação iniciou-se antes desse período, 
quando os EUA ampliaram seu apoio aos países subdesenvolvidos, após a segunda guerra mundial.

Ainda segundo Fischer, esse processo foi marcado por dois momentos históricos. O primeiro, pelo governo de Getúlio Vargas, que teve um caráter nacionalista. O segundo, pelo governo Juscelino Kubitschek, com caráter internacionalista. Neste último período, o processo de industrialização se acentuou, sobretudo devido à importação de tecnologia norte-americana.

O Parecer 307, aprovado pelo Conselho Federal de Educação em 8 de julho de 1966, fixou o primeiro currículo mínimo do Curso de Administração, institucionalizando, assim, a profissão e formação de Técnico em Administração. O currículo procurou agrupar matérias de cultura geral, matérias instrumentais e de formação profissional. Este currículo mínimo do Curso de Administração, que habilitava para o exercício da profissão de Técnico de Administração, seria constituído das seguintes matérias: matemática, estatística, contabilidade, teoria econômica; economia brasileira, psicologia aplicada à administração, sociologia aplicada à administração, instituições de direito público e privado (incluindo noções de ética administrativas), legislação social, legislação tributária; teoria geral da administração, administração financeira e orçamento, administração de pessoal, bem como administração de material.

Neste currículo mínimo, as matérias proporcionam uma formação especialista, tendo em vista que até a sociologia e psicologia, disciplinas humanas, não são vistas em seu “estado puro”, mas sim aplicadas à administração. Para Reinert (2002, p. 185), por exemplo, cada disciplina deveria ser ministrada de modo a contemplar primeiramente seus fundamentos mais essenciais. O autor (p. 186) questiona "como pode ser possível aplicar uma teoria numa área da administração se as bases da mesma são completamente desconhecidas do aluno?". Esse questionamento se faz em relação a disciplinas como "sociologia, psicologia ou economia, aplicada à administração" sem que antes o estudante tenha "contemplado seus fundamentos mais essenciais".

Porém, as escolas possuem liberdade para desenvolver um outro tipo de formação, através do acréscimo de matérias específicas. Segundo o Parecer $n^{\circ}$ 307, "a atividade administrativa se caracteriza pela grande diversificação das operações e pelo nível de especialização de cada um de seus ramos".

A atividade administrativa é tão diversificada, que Reinert (2002) chama a atenção para a grande quantidade de autores, das mais diversas áreas de formação, que vêm escrevendo com grande êxito sobre a administração.

A pobreza epistemológica em que se encontra a administração decorre, para Sartor (2004), da ausência do componente humanista-filosófico na gestão de 
toda a organização. A ausência filosófica gerou um engessamento intelectual, com grandes perdas humanísticas, não só na administração, mas em quase todas as áreas do conhecimento humano.

\section{Metodologia}

A presente pesquisa tratou de um estudo de caso, uma vez que se restringiu a uma única unidade, a Universidade Federal de Santa Catarina. Esta investigação teve como principal finalidade investigar a formação humanista do Curso de Graduação em Administração da UFSC.

A pesquisa exploratório-descritiva foi utilizada visando descrever quais áreas do conhecimento, com as respectivas disciplinas, estavam envolvidas no currículo do Curso de Graduação em Administração da UFSC. Deste modo, realizou-se um levantamento, buscando conhecer, o primeiro currículo disponível deste curso, datado de 1978, nos arquivos da Pró-Reitoria de Ensino e o último, do segundo semestre do ano de 2006, coletado no site eletrônico da UFSC.

Convencionou-se, nesta pesquisa, que as disciplinas com formação humanista seriam apenas aquelas oriundas do Centro de Filosofia e Ciências Humanas da UFSC, unidade devidamente habilitada para esta formação, representada pelos cursos de filosofia, psicologia, história, geografia, ciências sociais. Isso não significa que o Curso de Administração não pudesse estar trabalhando conteúdos de formação humanista com seus estudantes, mesmo à revelia da estruturação universitária atual, preconizada na legislação. A identificação desta realidade, no entanto, seria muito difícil.

\subsection{Coleta e Análise dos dados}

Os dados foram obtidos a partir de pesquisa documental do currículo do Curso de Graduação em Administração da UFSC, na Pró-Reitoria de Ensino e nas páginas da Internet da própria Universidade. Nos currículos, foram identificadas as disciplinas de cada Departamento / Centro de Ensino e sua respectiva carga horária.

Os currículos foram analisados individualmente, identificando-se o percentual que cada matéria representava no total de horas aula do curso. Elas se encontravam (como se encontram até hoje) dispostas no curso em forma de códigos alfa numéricos. A matéria CAD 5218, por exemplo, referia-se à “Administração de Marketing” obrigatória para o curso de Administração do Centro Sócio Econômico. Através do código alfa foi identificada a origem de 
cada matéria, de qual Departamento ela é proveniente e a que Centro de Ensino ela pertence. Depois de concluída a identificação e seleção das matérias, estas foram agrupadas em um único bloco por similaridade de código alfa. Para compor o objetivo desta pesquisa todo este bloco foi considerado como uma disciplina. Fundamentados na leitura de Paviani e Botomé (1993), os autores deste trabalho convencionaram que cada Departamento de Ensino constituiria uma grande área disciplinar.

De acordo com esse entendimento, a soma de todas as horas/aulas do Departamento de Ensino representa o total que "a disciplina", tem, também, na visão de Paviani e Botomé, dentro de uma estrutura curricular que o estudante deverá cursar. A divisão do total das horas/aulas do Departamento de Ensino pelo total das horas/aula de todos os demais Departamentos indica o percentual de horas/aulas por curso, de cada Departamento dentro do currículo. Sendo o conjunto de matérias de um Departamento uma única disciplina, obteve-se, assim, o percentual de cada disciplina em relação às demais, dentro de um currículo.

Posteriormente, os Departamentos de Ensino foram agrupados em seus respectivos Centros de Ensino. Este processo objetivou identificar quais os Centros que compunham o currículo do curso e qual o percentual das disciplinas do Centro de Filosofia e Ciências Humanas em relação ao total de disciplinas dos demais Centros de Ensino, pois esta relação indicou a formação humanística do Curso de Graduação em Administração da UFSC.

Para atingir o objetivo desta pesquisa, elaborou-se um comparativo do primeiro currículo disponível, a partir de 1974 de cada curso de graduação (e não só do curso de administração) com o último currículo, correspondente ao segundo semestre do ano de 2006, em termos de presença das disciplinas do Centro de Filosofia e Ciências Humanas, em relação ao total de disciplinas dos demais Centros de Ensino. Assim, pode-se identificar o aumento ou diminuição de disciplinas indicativas de formação humanista na atual proposta curricular do Curso de Graduação em Administração neste contexto em relação à sua primeira proposta curricular.

\section{O Curso de Graduação em Administração da Universidade Federal de Santa Catarina}

A seguir serão apresentados os resultados da pesquisa realizada nos currículos do Cursos de Graduação em Administração da UFSC. 


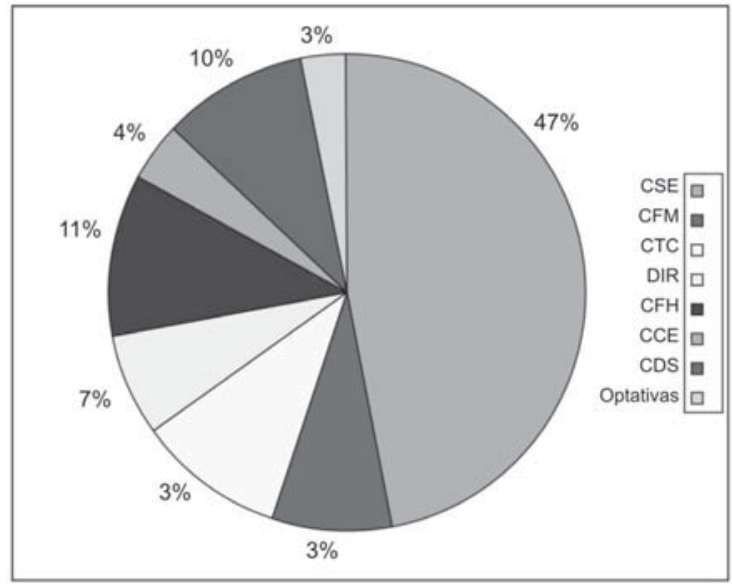

Fonte: Buss (2006)

Gráfico 1 - Disposição dos Centros no Curso de Administração - 1978

Este gráfico demonstra que o currículo de 1978, o primeiro disponível do Curso de Administração, era bastante generalista, com disciplinas de vários outros Centros de Ensino da UFSC. Nos 47\% de disciplinas do próprio Centro estavam incluídas $8,81 \%$ referentes a estágios obrigatórios, que eram realizadas no Departamento de Ciências da Administração.

As disciplinas advindas do Centro de Filosofia e Ciências Humanas (CFH) representavam $11 \%$ do percentual de disciplinas do Curso de Administração, um bom percentual quando comparado com o total geral. O Centro Tecnológico (CTC) e o Centro de Desportos (CDS) representavam 10\% cada um no total de disciplinas do curso, seguido pelo Centro de Ciência Física e Matemática (CFM) com $8 \%$, Centro de Ciências Jurídicas (DIR) com 7\%, Centro de Comunicação e Expressão (CCS) com 4\% e disciplinas optativas com 3\%.

O Currículo do Curso de Administração era dividido em dois ciclos, um básico e outro profissionalizante. O ciclo básico, que ia até a terceira fase, era composto por disciplinas que objetivavam fornecer uma melhor formação, principalmente humana e geral, antes que o estudante ingressasse nas disciplinas profissionalizantes. Entre estas disciplinas encontravam-se: Filosofia, Metodologia Científica, Português, Inglês, Sociologia, Práticas Desportivas, Estatística, entre outras. Dos $8 \%$ de disciplinas oriundas do $\mathrm{CFH}$, mais da metade se encontravam neste ciclo básico. 
Tabela 1 - Disposição dos Departamentos no Curso de Administração - 1978

\begin{tabular}{|c|c|c|}
\hline Departamentos & Total de hs/aula & \% aulas/curso \\
\hline EPB & 60 & 1,76 \\
\hline FIL & 75 & 2,20 \\
\hline LLV & 60 & 1,76 \\
\hline LLE & 75 & 2,20 \\
\hline PDS & 210 & 6,17 \\
\hline DPS & 120 & 3,52 \\
\hline MTM & 270 & 7,93 \\
\hline SCL & 180 & 5,29 \\
\hline CEC & 300 & 8,81 \\
\hline CCN & 285 & 8,37 \\
\hline CAD & 765 & $\mathbf{2 2 , 4 7}$ \\
\hline CNN & 300 & 8,81 \\
\hline DPC & 225 & 6,61 \\
\hline PSI & 45 & 1,32 \\
\hline EIN & 45 & 1,32 \\
\hline Optativas & 90 & 2,64 \\
\hline Estágio CAD & 300 & 8,81 \\
\hline TOTAIS & 3405 & $\mathbf{1 0 0 , 0 0}$ \\
\hline
\end{tabular}

Fonte: Buss (2006)

A tabela 1 apresenta o percentual que cada departamento representa do currículo do curso de administração do ano de 1978. O currículo do curso de administração era formado por 15 departamentos, que se originavam de diferentes centros de ensino. O departamento principal que compunha esse currículo era o de administração (CAD) com 22,47\% de disciplinas. Os outros departamentos possuíam representação significativa, o que tornava o curso mais generalista e multidisciplinar.

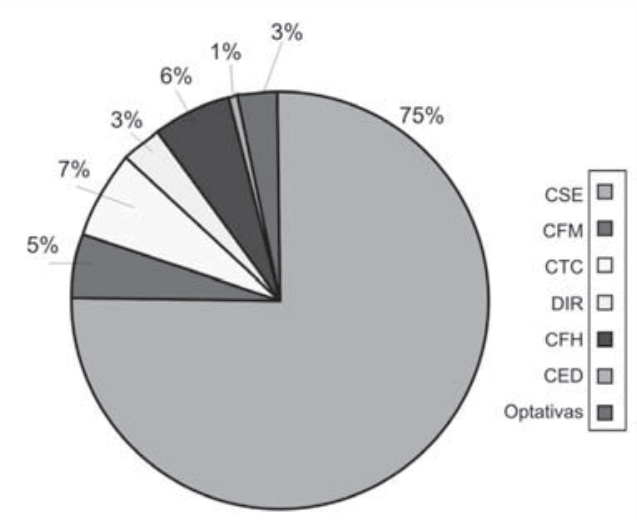

Fonte: Buss (2006)

Gráfico 2 - Disposição dos Centros no Curso de Administração - 2006 
No gráfico 2, que apresenta a situação do currículo em 2006, o curso passa a ser mais especializado, concentrando 75\% das disciplinas no próprio Centro, uma diferença de $35 \%$ em comparação com o currículo de 1978 . Desses $75 \%$, 9,47\% são de estágios, realizados no Departamento de Ciências da Administração.

Ocorreu uma redução significativa de disciplinas de todos os demais Centros. As disciplinas humanas sofrem uma redução de $5 \%$, ficando em $6 \%$, mesmo assim relativamente alta quando se compara o Curso de Administração com os demais cursos da UFSC. O Centro Tecnológico representa agora 7\% do total de disciplinas do curso, o Centro de Ciência Física e Matemática, reduziu-se para 5\%, o Centro de Ciências Jurídicas caiu de 7\% para 3\%, as optativas representam 3\%, e houve a inclusão de disciplinas do Centro de Educação (CED), que participam com $1 \%$ do total de disciplinas do curso. O Centro de Desportos e o Centro de Comunicação e Expressão não possuem nenhuma disciplina no currículo do ano 2006 do Curso de Administração.

Tabela 2 - Disposição dos Departamentos no Curso de Administração - 2006

\begin{tabular}{|c|c|c|}
\hline Departamentos & Total de hs/aula & \% aulas/curso \\
\hline CAD & $\mathbf{1 6 8 0}$ & $\mathbf{5 3 , 0 3}$ \\
\hline CNM & 216 & 6,82 \\
\hline CCN & 180 & 5,68 \\
\hline MTM & 144 & 4,55 \\
\hline INE & 144 & 4,55 \\
\hline DIR & 108 & 3,41 \\
\hline PSI & 72 & 2,27 \\
\hline SPO & 72 & 2,27 \\
\hline EPS & 72 & 2,27 \\
\hline CIN & 36 & 1,14 \\
\hline FIL & 36 & 1,14 \\
\hline Estágio CAD & 300 & 9,47 \\
\hline Optativas & 108 & 3,41 \\
\hline TOTAIS & $\mathbf{3 1 6 8}$ & $\mathbf{1 0 0 , 0 0}$ \\
\hline
\end{tabular}

Fonte: Buss (2006)

Esta tabela demonstra uma redução de 15 para 11 departamentos que compunham o currículo de administração. Além desta redução pode ser percebido o aumento de disciplinas do departamento de administração de 22,47\% 
para 53,03\%, excluindo desta forma alguns departamentos e reduzindo a participação de outros na formação do currículo. Esse aumento de 30,56\% de disciplinas do departamento de administração caracteriza um reducionismo da multidisciplinaridade e humanismo, fazendo com que o curso se torne mais especialista. Esta superespecialização do estudante faz com que o mesmo tenha um menor conhecimento das demais áreas.

\section{Conclusão}

Este estudo se propôs pesquisar a formação humanista no Curso de Graduação em Administração da Universidade Federal de Santa Catarina. Os resultados apurados, analisados e interpretados, demonstram o que segue:

No Curso de graduação em Administração foi encontrado um baixo índice de disciplinas humanas. Devido ao seu histórico multidisciplinar, com passagens da teoria administrativa pela psicologia e pela sociologia esperava-se uma formação mais humanista deste curso.

Conclui-se, através dos dados pesquisados, e através da elaboração de gráficos e tabelas, que tiveram o intuito de fundamentar a análise, que o currículo do Curso de Graduação em Administração da UFSC reduziu a participação de disciplinas de formação humanista em relação ao primeiro currículo datado de 1978.

Para o curso de Administração, a socialização do saber amplo se faz cada vez mais necessária, já que se trata de um curso multidisciplinar por natureza, formado pelas mais diversas áreas de conhecimento, particularmente pelas denominadas ciências humanas e sociais.

A pesquisa ressaltou, de modo claro, de que infelizmente o que é válido atualmente é o treinamento técnico-científico, com a formação voltada profissionalmente para as necessidades do mercado, distanciando-se cada vez mais o conhecimento amplo e a formação humanista do estudante universitário.

O conhecimento técnico não é discutível, é importante, mas não sozinho; precisa ter uma base sólida para poder ser estruturado. Empresas, organizações e instituições de ensino necessitam de profissionais que possuam muito mais que o conhecimento técnico; elas necessitam de formadores de opinião, com capacidade de comunicação oral e escrita, que saibam se relacionar e possuam grande capacidade criativa. Só que, para isso, é necessário destacar uma visão geral do saber, que não seja enclausurada em currículos fechados em determinada área específica do conhecimento. 


\section{Referências}

ABRÃO, Bernadette Siqueira. A história da filosofia. São Paulo: Nova Cultural, 2004.

ANASTASIOU, L. das G. C.; ALVES L. P. Processo de ensinagem na universidade: pressupostos para as estratégias de trabalho em aula. 3. ed. Joinville: UNIVILLE, 2004.

BASBAUM, Leoncio. Alienação e humanismo. 4. ed. São Paulo: Global, 1981.

BAZZO, W. A. Ciência, tecnologia e sociedade e o contexto da educação tecnológica. Florianópolis: UFSC, 1998.

BRASIL. Ministério da Educação. Reforma da educação brasileira. Disponível em: <http://www.portal.mec.gov.br> Acesso em: 08 nov.2005.

BUSS, Ricardo Niehues. A formação humanista no Curso de Graduação em Administração em relação aos demais cursos da Universidade Federal de Santa Catarina. 2006. 125 f. Dissertação (Mestrado) - Universidade Federal de Santa Catarina, Curso de Pós-Graduação em Administração, Florianópolis, 2006.

COELHO, Ildeu Moreira. Graduação: rumos e perspectivas. Disponível em: $<$ http://www.enecos.org.br/docs/graduacao_imoreira.doc> Acesso em: 05 jan. 2006.

CRIPPA, Adolpho. O problema da universidade. São Paulo: Convívio, 1966.

FERREIRA, Aurélio B. H. P. Novo dicionário da língua portuguesa. Rio de Janeiro: Nova Fronteira, 1975.

FISCHER, Tânia. O ensino de administração pública no Brasil: da tutela estrangeira à autonomia necessária. In: REUNIÃO NACIONAL DA ANPAD, Belo Horizonte, 1985. Florianópolis-SC: 1985. Ed. da UFSC, 1985.

FREIRE, Paulo. Pedagogia da autonomia: saberes necessários à prática educativa. São Paulo: Paz e Terra, 1996.

LINSINGEN, Irlan von. Novos modelos de produção e a formação do engenheiro: uma abordagem CTS. Disponível em: <http://www.emc.ufsc. br/ nepet/Artigos/Texto/Mod_Prod.htm> Acesso em: 22 out. 2005. 
MORIN, E. A cabeça bem feita: repensar a reforma, reformar o pensamento. 6. ed. Rio de Janeiro: Bertrand Brasil, 2002.

PAVIANI, Jayme; BOTOMÉ, Sílvio Paulo. Interdisciplinaridade: difusões conceituais e enganos acadêmicos. Caxias do Sul: EDUCS, 1993.

PAVIANI, Jayme; DAL RI JUNIOR, Arno. Globalização e humanismo latino. Porto Alegre: Edipucrs, 2000.

PIAGET, Jean. Psicologia e pedagogia. Rio de Janeiro: Forense Universitária, 2003.

REINERT, J. N. Cursos de graduação em administração: a necessidade de um novo enfoque. A gestão universitária em ambientes de mudanças na América do Sul. Blumenau: Nova Letra, 2002.

REINERT, J. N. Os aspectos críticos da administração científica e o seu obsoletismo. Florianópolis: Imprensa universitária da UFSC, 1981.

SANTOMÉ, Jurjo Torres. Globalização e interdisciplinaridade: o currículo integrado. Porto Alegre: Artmed, 1998.

SARTOR, V. V. D. B. Humanismo e dos compromissos intergeracionais. Repensando as Organizações: da formação à participação. Florianópolis: Fundação Boiteux, 2004.

SUWWAN, Leila. Para feminista, pensamento independente não tem espaço. Folha de S. Paulo, São Paulo, 27 mar. 2006. Entrevista. p. A14.

TEIXEIRA, Anísio. A universidade de ontem e de hoje. Revista Brasileira de Estudos Pedagógicos, Rio de Janeiro, v. 42, n. 95, jul./set. 1964.

TEIXEIRA, Anísio. Porque "Escola Nova". Boletim da Associação Bahiana de Educação, Salvador, n.1, 1930.

TOBIAS, José Antônio. Universidade: humanismo ou técnica? São Paulo: Herder, 1969.

UNIVERSIDADE FEDERAL DE SANTACATARINA- UFSC. Currículo Curso de Administração. Disponível em: < http://notes.ufsc.br/aplic/curGrad.nsf/ 27985f7d0220152b8525639200750d4d/abf428334b444fdd83256e14005f7509/ \$FILE/ADMINISTRACAO\%20(noturno)\%20\%5Bcurriculo\%2019951\%5D. pdf>. Acesso em: 20 nov. 2006.

UNIVERSIDADE FEDERAL DE SANTA CATARINA - UFSC. Legislação Educacional. Disponível em: $<$ http://notes.ufsc.br/aplic/edulei.nsf/viewLegislacao_PorTipo $>$. Acesso em: 15 set. 2005. 